\title{
Association between the p.V37I variant of GJB2 and hearing loss: a pedigree and meta-analysis
}

\author{
Na Shen ${ }^{1}$, Jing Peng ${ }^{1}$, Xiong Wang ${ }^{1}$, Yaowu Zhu ${ }^{1}$, Weiyong Liu ${ }^{1}$, Aiguo Liu ${ }^{2}$ and \\ Yanjun Lu ${ }^{1}$ \\ ${ }^{1}$ Department of Laboratory Medicine, Tongji Hospital, Tongji Medical College, Huazhong University of Science and Technology, \\ Wuhan 430030, China \\ ${ }^{2}$ Department of Otorhinolaryngology, Tongji Hospital, Tongji Medical College, Huazhong University of Science and Technology, \\ Wuhan 430030, China \\ Correspondence to: Aiguo Liv, email: aiguoliu309@163.com \\ Yanjun Lu, email: junyanlu_2000@163.com \\ Keywords: hearing loss (HL), GJB2, p.V37I, pedigree analysis, meta-analysis \\ Received: February 03, $2017 \quad$ Accepted: March 19, $2017 \quad$ Published: April 21, 2017 \\ Copyright: Shen et al. This is an open-access article distributed under the terms of the Creative Commons Attribution License \\ (CC-BY), which permits unrestricted use, distribution, and reproduction in any medium, provided the original author and source \\ are credited.
}

\section{ABSTRACT}

Pathogenic variants in the gap junction protein beta-2 (GJB2) gene are the most common cause of hearing loss. Of these, the p.V37I variant of GJB2 has a high allele frequency (up to 10\%) in East Asians. Characterization of the phenotypic spectrum associated with p.V37I, as well as the role of this variant in the onset of hearing loss could have a remarkable effect on future diagnostic strategies. Here, we performed a pedigree analysis of unrelated families exhibiting various hearing phenotypes, and then conducted a meta-analysis to comprehensively assess the association between the p.V37I and the risk of hearing loss. Pedigree analyses showed that both homozygous p.V37I variants, as well as compound heterozygous p.V37I with other GJB2 pathogenic variants, contributed to various phenotypes of hearing loss. Meanwhile, meta-analysis demonstrated that, compared with those in the wild type group, both p.V37I homozygotes and compound heterozygous p.V37I variants were at significantly higher risk of developing hearing loss (odds ratios = 7.14 and 3.63; $95 \%$ confidence intervals $=3.01-16.95$ and $1.38-9.54$, respectively). Conversely, heterozygous p.V37I variants alone did not increase the risk of hearing loss. Given the high allele carriage rate of p.V37I (up to $10 \%$ ) within the general population, our work not only provides information that might influence future genetic screening policies, but also offers insight into clinical risk evaluation and genetic counseling regarding hearing loss.

\section{INTRODUCTION}

Hearing loss (HL) is the most sensory defect that affects 1-3 in every 1,000 newborns worldwide, and half of these cases are attributed to genetic factors [1]. Notably, while a large number of HL-related genes have been identified, the gap junction protein beta 2 (GJB2) gene accounts for nearly $20 \%$ of all cases of HL, as well as $50 \%$ of autosomal recessive non-syndromic HL, in many populations [2, 3]. GJB2 encodes the connexin 26 protein, which comprises a critical component of cochlear gap junctions, and is important to cell communication. To date, greater than 300 variants within GJB2 have been found to be associated with HL (http://www.hgmd.cf.ac.uk/ac/), including c.35delG, c.235delC, and c.176 191del16.

In particular, the p.V37I (c.109G $>A)$ variant of GJB2 has a high allele frequency (up to $10 \%$ ) among East Asian populations [4-6]. This variant, harboring a missense substitution from valine to isoleucine at codon 37, was first identified by Kelley et al. in 1998 [7]. Early studies regarded the p.V37I as a benign polymorphism, as it was observed in unaffected heterozygous controls [7-11]. However, the identification of increasing numbers of HL patients that are homozygous for p.V37I, or compound heterozygous 
for p.V37I and other GJB2 pathogenic variants, indicates that p.V37I likely increases the risk of HL, particularly for mild-to-moderate cases [6, 12-15]. Interestingly, a recent meta-analysis reported an insignificant association between the carriage rates of p.V37I and HL, which aroused wide concern regarding the pathogenicity of this variant [16].

Given the high allelic frequency of the p.V37I variant (up to $10 \%$ ), it is estimated that greater than five million East Asians suffer from HL due to homozygous or compound heterozygous carriage of this allele [6]. It is therefore imperative to evaluate the risks associated with p.V37I for clinical genetic counseling and public health assessment purposes. In this study, we performed a pedigree analysis of families with probands exhibiting various HL phenotypes, and then conducted a metaanalysis of sporadic HL to comprehensively evaluate the role of p.V37I in the risk of HL.

\section{RESULTS}

\section{Pedigree analyses}

Seven families carrying the p.V37I variant were included for pedigree analyses (Table 1 and Figure 1). There were five male and two female probands. Six probands were children ( 7 months- 9 years) and one proband was an adult (33 years). These probands exhibited both congenital and delayed-onset non-syndromic HL, and one member had sudden deafness. Bilateral and unilateral non-syndromic HL were also observed, with HL degrees of mild to moderate. Families $1-5$ had probands that were homozygous for p.V37I (S1-S5), while the probands of Families 6 and 7 had compound heterozygous p.V37I variants $(\mathrm{H} 1-\mathrm{H} 2)$. In this study, compound heterozygous p.V37I variants were defined as the p.V37I allele in a trans configuration with another pathogenic mutant allele of GJB2 gene. Pedigree analyses revealed that p.V37I was transmitted from heterozygous parents to their children, who suffered HL if he/she inherited two affected alleles (p.V37I homozygotes or compound heterozygous p.V37I variants). Meanwhile, siblings that inherited one affected allele retained normal hearing. These analyses strongly suggest that p.V37I increases the risk of HL through an autosomal recessive inheritance pattern.

\section{Meta-analysis on sporadic HL}

To further determine the detrimental effects of p.V37I, we performed a meta-analysis. A flow chart of the literature search is shown in Supplementary Figure 1. A total of 1,085 potentially relevant records were initially identified in our search. Of these, 391 duplicates and 644 irrelevant records were removed upon reviewing titles and abstracts, yielding 50 full-text articles for further evaluation. Seventeen studies were subsequently excluded because they provided no genetic data regarding the $\mathrm{p}$.V37I variant $(\mathrm{n}=$
7), they lacked sufficient information to estimate odds ratio $(\mathrm{OR})$ and $95 \%$ confidence interval $(\mathrm{CI})(\mathrm{n}=7)$, they lacked a parallel control group $(n=2)$, or their data overlapped with that of another study $(\mathrm{n}=1)$. Of the 33 remaining studies eligible for meta-analysis [5, 7-15, 17-39], 10 also provided genotypes of compound heterozygous p.V37I variants [8, 12, 13, 19, 21, 28, 33-35, 37].

As shown in Table 2, a total of 14,398 HL cases and 8,699 controls were included to evaluate the association between p.V37I and HL risk. Twenty of the studies were conducted in Asia (China, Japan, Malaysia and Indonesia) $[5,8,9,12-14,18,20,22-24,26,30,31$, 34-37, 39], while six were conducted in North America (United States and Canada) [7, 11, 15, 19, 28, 33], five in Europe (Portugal, Italy, Finland, France and Spain) [10, 17, 21, 25, 38], one in Latin America (Argentina) [32], and one in Oceania (Australia) [27]. Overall, there was a significant association between the $p . V 37$ I variant and increased risk of developing HL (Figure 2). Specifically, the A allele of p.V37I was associated with a 2-fold higher risk of developing $\mathrm{HL}$ than the $\mathrm{G}$ allele (Figure $2 \mathrm{~A}$; OR = $\left.1.91 ; 95 \% \mathrm{CI}=1.42-2.56 ; P_{\text {heterogeneity }}<0.001 ; I^{2}=74.9 \%\right)$. Moreover, compared with individuals with wild type, p.V37I homozygotes (Figure 2C; OR $=7.14 ; 95 \% \mathrm{CI}=$ 3.01-16.95; $P_{\text {heterogeneity }}<0.001 ; I^{2}=70.9 \%$ ), but not p.V37I heterozygotes (Figure 2B; OR $=1.18 ; 95 \% \mathrm{CI}=0.92-1.52$; $\left.P_{\text {heterogeneity }}=0.034 ; I^{2}=35.5 \%\right)$, had a significantly higher risk (7.14-fold greater) of developing HL. Similar results were obtained using the recessive model (Figure 2D; $\mathrm{OR}=7.02 ; 95 \% \mathrm{CI}=2.95-16.66 ; P_{\text {heterogeneity }}<0.001 ; I^{2}=$ $71.1 \%$ ). Sensitivity analyses demonstrated that our results were quite stable (Supplementary Figure 2A-2D) and no obvious publication biases were found (all $P>0.10$ ).

Furthermore, we evaluated the association between compound heterozygous p.V37I variants on HL risk. Ten eligible studies comprising of 6,762 cases and 4,211 controls were included (Table 3). Notably, our results suggest that people harboring compound heterozygous p.V37I variants have a 3.63-fold higher risk of HL than those without these variants (Figure 3; OR $=3.63 ; 95 \% \mathrm{CI}=1.38-9.54$; $P_{\text {heterogeneity }}=0.060 ; I^{2}=44.9 \%$ ). These results were strongly supported by sensitivity analyses (Supplementary Figure 3), and no publication bias was found $(P=0.152)$.

\section{DISCUSSION}

In this study, we demonstrated that bi-allelic or compound heterozygous p.V37I variants are associated with increased risk of various HL phenotypes, and quantified the risk associated with these variants and development of HL.

Our pedigree analyses indicated that p.V37I can cause HL as either a homozygous variant or as compound heterozygous with other pathogenic variants in GJB2. Functional studies performed in cells and mouse models support this conclusion [40-42]. In consistent with previous reports $[6,12-14]$, we observed that the HL 
Table 1: Clinical characteristics of probands carrying the p.V37I variant

\begin{tabular}{lcccccc}
\hline ID & Sex & Age & p.V37I status & Onset & Site & Degree \\
\hline S1 & Female & 7 months & Homozygote & Congenital & Bilateral & Moderate \\
S2 & Male & 8 years & Homozygote & Congenital & Bilateral & Mild \\
S3 & Male & 9 years & Homozygote & Congenital & Unilateral & Mild \\
S4 & Male & 33 years & Homozygote & Delayed-onset & Bilateral & Moderate \\
S5 & Male & 8 years & Homozygote & Sudden deafness & Bilateral & Mild \\
H1 & Female & 7 years & p.V37I/c.176_191del16 & Delayed-onset & Bilateral & Mild \\
H2 & Male & 3 years & p.V37I/c.235delC & Congenital & Bilateral & Moderate \\
\hline
\end{tabular}

a The severity of deafness of proband S5 was $30 \mathrm{~dB}$ at the left ear, and $31.25 \mathrm{~dB}$ at the right ear, so his degree of HL was considered as mild.

Family 1

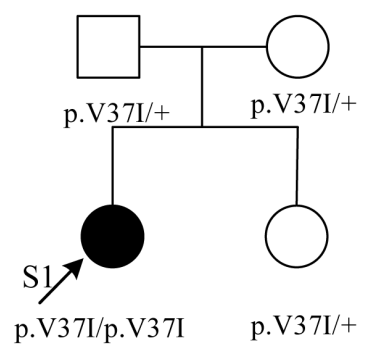

Family 4

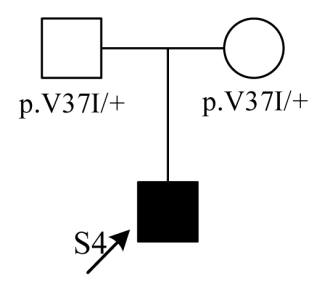

p.V37I/p.V37I

Family 6

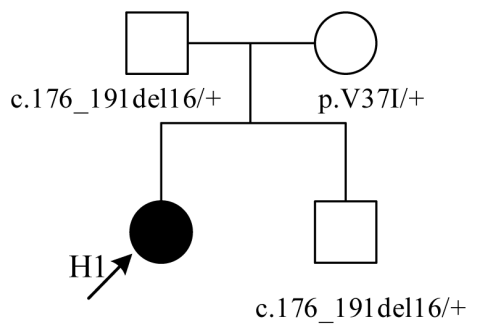

c.176_191del16/p.V37I
Family 2

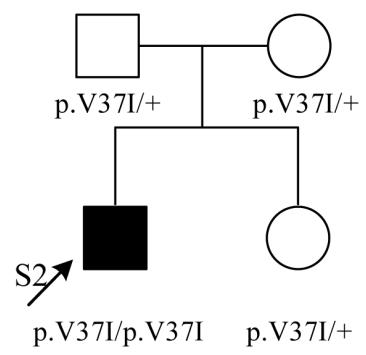

Family 5

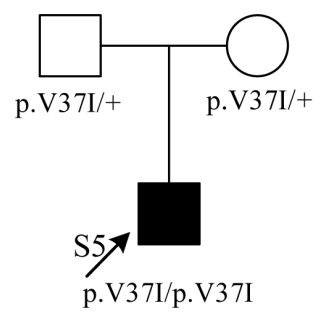

Family 7

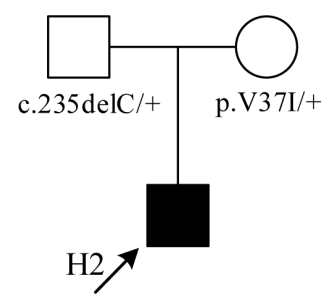

c. $235 \mathrm{delC} / \mathrm{p}$. V37I

Figure 1: Pedigree analyses for seven unrelated families carrying the p.V37I variant. Five probands (S1-S5) carried two p.V37I alleles as homozygotes. Two probands $(\mathrm{H} 1, \mathrm{H} 2)$ carried the $\mathrm{p}$.V37I allele in a trans configuration with another well-known pathogenic mutant allele of GJB2, as compound heterozygotes. The hearing level of S1 was recorded by auditory brainstem responses (ABR) due to her very young age (7 months). The hearing level of $\mathrm{H} 2$ was recorded by the auditory steady-state responses (ASSR) because of his poor cooperation in pure-tone audiometry (PTA) test. Sanger sequencing results of pedigree analyses were shown in Supplementary Figure 4. 
Table 2: Characteristics of studies included for meta-analysis

\begin{tabular}{|c|c|c|c|c|c|c|c|}
\hline First author & $\begin{array}{c}\text { Publication } \\
\text { year }\end{array}$ & Country & $\begin{array}{l}\text { Geological } \\
\text { area }\end{array}$ & Population & Cases & Controls & $P_{H W E}$ \\
\hline Chen [39] & 2016 & China & Asia & Children and adults & 50 & 53 & 0.399 \\
\hline Caroça [38] & 2016 & Portugal & Europe & Children and adults & 134 & 177 & 0.970 \\
\hline Huang [12] & 2015 & $\begin{array}{l}\text { Shanghai, } \\
\text { China }\end{array}$ & Asia & Infants & 300 & 484 & 0.747 \\
\hline Huang [13] & 2015 & China & Asia & Infants and adults & 3,864 & 600 & 0.318 \\
\hline Chai [14] & 2015 & China & Asia & Infants and adults & 945 & 1,500 & 0.557 \\
\hline Chen [37] & 2014 & China & Asia & Infants and child & 107 & 61 & 0.486 \\
\hline Zainal [36] & 2012 & Malaysia & Asia & Children & 32 & 37 & 0.479 \\
\hline Zhang [35] & 2011 & China & Asia & Children and adults & 236 & 107 & 0.765 \\
\hline $\mathrm{Wu}[34]$ & 2011 & China & Asia & Infants & 38 & 979 & 0.139 \\
\hline Schimmenti [33] & 2011 & United States & North America & Infants & 1,177 & 1,177 & 0.884 \\
\hline Tsukada [5] & 2010 & Japan & Asia & Infants and children & 1,343 & 252 & 0.924 \\
\hline Dalamon [32] & 2010 & Argentina & Latin America & NR & 252 & 50 & 0.943 \\
\hline Dai [31] & 2009 & China & Asia & Children and adults & 1,372 & 301 & NA \\
\hline Chen [30] & 2009 & China & Asia & NR & 115 & 109 & NA \\
\hline Yang [29] & 2007 & China & Asia & NR & 260 & 120 & $<0.001$ \\
\hline Tang [28] & 2006 & United States & North America & NR & 610 & 294 & 0.004 \\
\hline Huculak [15] & 2006 & Canada & North America & NR & 40 & 100 & 0.751 \\
\hline Dahl [27] & 2006 & Australia & Oceania & Children & 48 & 90 & NA \\
\hline Snoeckx [26] & 2005 & Indonesia & Asia & $\begin{array}{l}\text { Patients: }<20 \text { years } \\
\text { old; Control: adults }\end{array}$ & 120 & 100 & 0.879 \\
\hline Ravecca [25] & 2005 & Italy & Europe & Children and adults & 39 & 40 & 0.936 \\
\hline Xiao [24] & 2004 & China & Asia & NR & 131 & 100 & 0.100 \\
\hline $\begin{array}{l}\text { Wattanasirichaigoon } \\
\text { [11] }\end{array}$ & 2004 & United States & North America & Children and adults & 166 & 205 & 0.181 \\
\hline Shi [23] & 2004 & China & Asia & $\begin{array}{l}\text { Patients: infants; } \\
\text { Control: NR }\end{array}$ & 20 & 50 & 0.827 \\
\hline Ohtsuka [22] & 2003 & Japan & Asia & NR & 1,227 & 147 & NA \\
\hline Lopponen [21] & 2003 & Finland & Europe & $\begin{array}{l}\text { Patients: children; } \\
\text { Control: NR }\end{array}$ & 71 & 313 & NA \\
\hline Hwa [20] & 2003 & China & Asia & NR & 324 & 432 & NA \\
\hline $\mathrm{Wu}[19]$ & 2002 & United States & North America & $\begin{array}{l}\text { Patients: children; } \\
\text { Control: NR }\end{array}$ & 324 & 100 & NA \\
\hline Liu [18] & 2002 & China & Asia & $\begin{array}{l}\text { Patients: children } \\
\text { and adults; Control: } \\
\text { NR }\end{array}$ & 210 & 200 & NA \\
\hline
\end{tabular}




\begin{tabular}{lccccccc}
\hline First author & $\begin{array}{c}\text { Publication } \\
\text { year }\end{array}$ & Country & $\begin{array}{c}\text { Geological } \\
\text { area }\end{array}$ & Population & Cases & Controls & $\boldsymbol{P}_{H W E}$ \\
\hline Marlin [17] & 2001 & France & Europe & $\begin{array}{c}\text { Patients: children; } \\
\text { Control: NR } \\
\text { Patients: children; } \\
\text { Control: NR }\end{array}$ & 96 & 116 & 0.963 \\
Rabionet [10] & 2000 & Italy and Spain & Europe & Patients: children & 100 & NA \\
Kudo [9] & 2000 & Japan & Asia & $\begin{array}{c}\text { and adults; Control: } \\
\text { NR }\end{array}$ & 78 & 63 & NA \\
Abe [8] & 2000 & Japan & Asia & NR & 35 & 96 & 0.918 \\
Kelley [7] & 1998 & United States & North America & NR & 58 & 96 & 0.959 \\
\hline
\end{tabular}

NR: not reported; NA: not available; $P_{H W E}: P$ value for test of Hardy-Weinberg equilibrium.

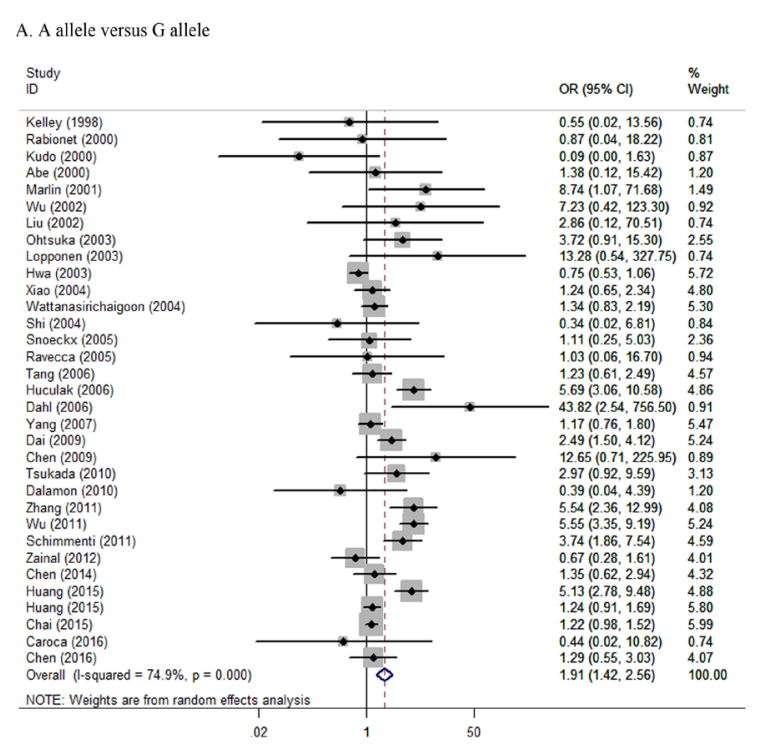

B. GA versus $\mathrm{GG}$
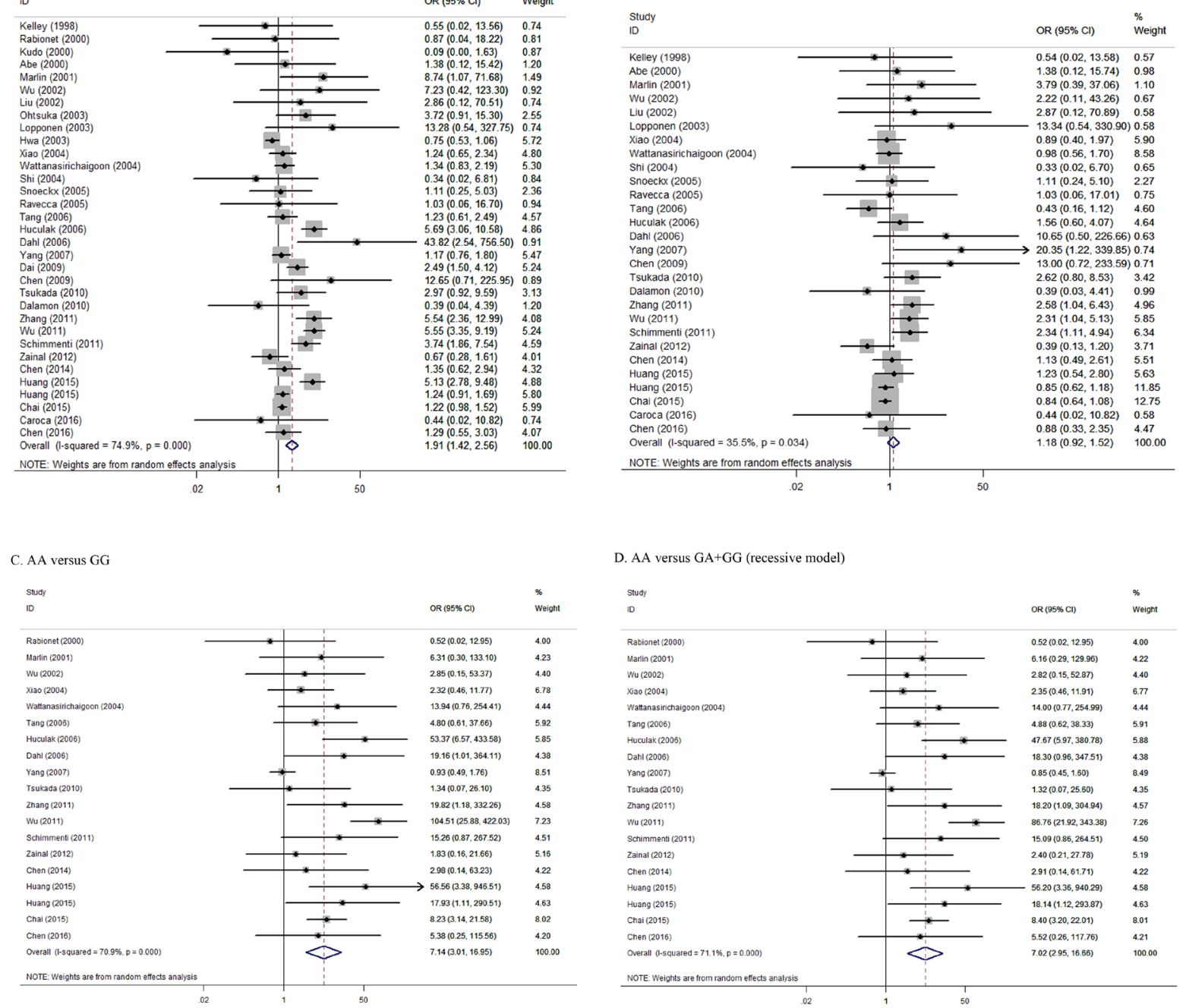

Figure 2: Forest plots of the effects of p.V37I on HL risk under the (A) allelic, (B and C) codominant, and (D) recessive models. Allelic model referred to A allele versus G allele. Codominant model referred to GA genotype versus GG genotype (B), or AA genotype versus GG genotype (C). Recessive model referred to AA genotype versus GA+GG genotype. 
Table 3: Characteristics of studies for the association between compound heterozygous p.V37I variants and HL risk

\begin{tabular}{|c|c|c|c|c|c|c|}
\hline First author & $\begin{array}{c}\text { Publication } \\
\text { year }\end{array}$ & Country & Population & Cases & Controls & Types \\
\hline Huang [12] & 2015 & China & Infants & 300 & 484 & $\begin{array}{c}\text { p.V37I/c.235delC, p.V37I/ } \\
\text { c.299_300delAT, p.V37I/c.79G }>\text { A } \\
\text { p. } . \text { V37I/c. }(79 \mathrm{G}>\mathrm{A}+341 \mathrm{~A}>\mathrm{G})\end{array}$ \\
\hline Huang [13] & 2015 & China & $\begin{array}{l}\text { Infants and } \\
\text { adults }\end{array}$ & 3,864 & 600 & $\begin{array}{c}\text { p.V37I/c.235delC, p.V37I/c.299delAT, } \\
\text { p.V37I/p.R143W, p.V37I/c.176del16, } \\
\text { p.V37I/c.512insAACG, p.V37I/p.T86R, } \\
\text { p.V37I/p.W77* }\end{array}$ \\
\hline Chen [37] & 2014 & China & $\begin{array}{l}\text { Infants and } \\
\text { child }\end{array}$ & 107 & 61 & $\begin{array}{c}\text { p.V37I/c.235delC, p.V37I/c.608T }>\text { C } \\
\text { p.V37I/c. }(79 \mathrm{G}>\mathrm{A} ; 341 \mathrm{~A}>\mathrm{G})\end{array}$ \\
\hline Zhang [35] & 2011 & China & $\begin{array}{l}\text { Children and } \\
\text { adults }\end{array}$ & 236 & 107 & $\begin{array}{l}\text { p.V37I/c.235delC, p.V37I/c.427C }>\text { T, } \\
\text { p.V27I/p.V37I/p.E114G, p.V27I/p.V37I, } \\
\text { p.V37I/p.I203T, p.V27I/p.V37I/p.V84M }\end{array}$ \\
\hline $\mathrm{Wu}[34]$ & 2011 & China & Infants & 38 & 979 & p.V37I/c.235delC \\
\hline Schimmenti [33] & 2011 & $\begin{array}{l}\text { United } \\
\text { States }\end{array}$ & Infants & 1,177 & 1,177 & p.V37I/p.L90P, p.V37I/p.(V27I, E114G) \\
\hline Tang [28] & 2006 & $\begin{array}{l}\text { United } \\
\text { States }\end{array}$ & NR & 610 & 294 & $\begin{array}{c}\text { p.V37I/c.35delG, p.V37I/p.L90P, } \\
\text { p.V37I/p.R216fsX232, p.V37I/p.V27I, } \\
\text { p.V37I/(p.V27I+p.E114G), p.V37I/p. } \\
\text { I203T }\end{array}$ \\
\hline Lopponen [21] & 2003 & Finland & $\begin{array}{l}\text { Patients: } \\
\text { children; } \\
\text { Control: NR }\end{array}$ & 71 & 313 & p.V37I/p.M34T \\
\hline $\mathrm{Wu}[19]$ & 2002 & $\begin{array}{l}\text { United } \\
\text { States }\end{array}$ & $\begin{array}{l}\text { Patients: } \\
\text { children; } \\
\text { Control: NR }\end{array}$ & 324 & 100 & p.V37I/p.M34T, p.V37I/c.167delT \\
\hline Abe [8] & 2000 & Japan & NR & 35 & 96 & p.V37I/p.R143W, p.V37I/c.235delC \\
\hline
\end{tabular}

NR: not reported.

ID
Itudy

Figure 3: Forest plots of the effects of compound heterozygous p.V37I variants on HL risk. Compound heterozygous p.V37I variants referred to the heterozygous p.V37I allele in a trans configuration with another well-known pathogenic mutant allele of GJB2 gene. 
phenotypes associated with p.V37I varied by onset type, disease site, and degree of HL, implying that other causes, especially environmental factors, influence p.V37Imediated onset of HL. Notably, we also found that homozygous p.V37I might give rise to sudden deafness in children. Indeed, similar results were reported in a recent study [39]. As such, p.V37I might be considered as a potential cause of sudden onset of deafness in future cases.

To quantify the pathogenic association between p.V37I and HL risk, we performed a meta-analysis. In keeping with previous cohort studies and functional experiments, our results supported the conclusion that the p.V37I variant significantly increases an individual's risk of developing HL. Compared with wild type individuals, the p.V37I homozygote group, but not the heterozygote group, showed a significantly greater likelihood of developing HL. This could explain why p.V37I heterozygotes are prevalent among the general healthy population, while bi-allelic p.V37I variants are found predominantly in patients with HL. Notably, our results also indicate that the compound heterozygous p.V37I variants are associated with a nearly four-fold greater risk of developing HL, compared to wild type individuals. In view of the high prevalence of p.V37I and the large number of other GJB2 pathogenic variants, our findings indicate that previous reports have likely underestimated HL risk in human populations. Compared with the previous meta-analysis [16], our work included more eligible studies and quantified the risky effects of p.V37I on HL in more detail.

The major strengths of our work were the variable phenotypic spectrum associated with p.V37I and that a large population (23,097 participants) was used to evaluate the association between this variant and HL risk. However, our results should be interpreted with caution. First, only commonly known HL-related variants (variants within the GJB2, SLC26A4, $12 S$ rRNA, and GJB3 coding regions) were screened in our pedigree analysis. Second, the number of studies regarding compound heterozygous p.V37I variants evaluated herein was insufficient to further explore the concrete effects of particular compound variant types on $\mathrm{HL}$ risk. Third, although both our study and previous reports found that $\mathrm{p} . \mathrm{V} 37 \mathrm{I}$ is associated with various HL phenotypes, the specific mechanism by which this variant promotes HL, such as interactions between p.V37I and other genetic or environmental factors, remains unclear. Further studies are therefore needed to address these issues.

In summary, our work strongly suggests a pathogenic role for $\mathrm{p}$.V37I in various HL phenotypes and provides a quantitative assessment of the risk associated with carriage of this variant and development of HL. Considering the high carriage rate of p.V37I within the general population, these findings provide compelling information that should influence future genetic screening policy and that offer insights into clinical risk evaluation and genetic counseling.

\section{MATERIALS AND METHODS}

\section{Study participants and ethical statement}

For this study, we recruited seven unrelated probands with non-syndromic, sensorineural hearing loss, and their family members. Each participant provided written informed consent. For underage participants, written informed consent was obtained from their parents. Our study was approved by the Medical Ethics Committee of Tongji Hospital, Tongji Medical College, Huazhong University of Science and Technology. All procedures were performed according to the ethical guidelines for human subjects research.

\section{Clinical and audiometric evaluation}

All participants were subjected to physical and neurological examinations to exclude syndromic deafness. Each participant's level of hearing was assessed via a comprehensive auditory evaluation, such as by otoscope examination, tympanometry, or pure-tone audiometry (PTA). For very young participants, auditory brainstem responses (ABR) and/or auditory steady-state responses (ASSR) were recorded. Degree of hearing loss was estimated as the average hearing levels at 0.5, 1.0, 2.0, and $4.0 \mathrm{kHz}$ for the better ear. Severity of hearing loss was categorized as normal $(<25 \mathrm{~dB})$, mild $(26-40 \mathrm{~dB})$, moderate $(41-70 \mathrm{~dB})$, severe (71-95 dB), or profound ( $>95 \mathrm{~dB}$ ). In addition, we defined sudden deafness as over $30 \mathrm{~dB}$ of sensorineural hearing loss involving at least three frequencies occurring less than 72 hours [43].

\section{DNA extraction and mutation analysis}

Genomic DNA was extracted from anticoagulant peripheral blood by the QIAamp DNA blood mini kit (Qiagen, Germany). For mutation screening, the entire coding region and flanking sequences of four commonly mutated genes, GJB2, SLC26A4, $12 S$ rRNA, and GJB3, were polymerase chain reaction (PCR) amplified and then subjected to bidirectional sequencing with an ABI 3500 DNA sequencer (Applied Biosystems). The primers and PCR conditions used for these analyses are described in detail in Supplementary Table 1. Sanger sequencing results of pedigree analyses were shown in Supplementary Figure 4.

\section{Meta-analysis on sporadic HL}

We further performed a meta-analysis to determine the detrimental effects of p.V37I on sporadic HL, according to the guidelines of Preferred Reporting Items for Systematic Reviews and Meta-Analyses (PRISMA) [44]. A structured literature search was conducted of articles published through November 2016 using the PubMed, Web of Science, and EMBASE databases and the following search items: "GJB2 OR connexin 26", 
"polymorphism OR variant OR mutation", "hearing loss OR deafness", and "case-control OR cohort OR population". Only English language articles were included. The inclusion criteria were: (i) studies that investigated the association between p.V37I and HL under a case-control or cohort design; (ii) studies that reported genotypes or allelic data for p.V37I to estimate OR and $95 \%$ CI. In cases of overlapping populations, the study with the largest sample size was included. We used OR as the effect measure and combined data using a randomeffects model. Hardy-Weinberg equilibrium (HWE) in the controls was checked by $\chi^{2}$ test. Meanwhile, Cochran $\chi^{2}$ test and $I^{2}$ values were used to evaluate the heterogeneity between studies. Sensitivity analyses and publication bias assessment were also conducted. All statistical analyses were performed using Stata 12.1 software (StataCorp, College Station, TX, USA), and $P \leq 0.05$ was considered significant for all tests.

\section{Author contributions}

A.L. and Y.L. conceived and designed this study. N.S., A.L. and Y.L. recruited the study subjects and collected their characteristics and examination results. Y.Z. and W.L. extracted DNA. N.S. and J.P. conducted mutation analyses. J.P. and X.W. performed literature search, study selection and data extraction. X.W. and Y.Z. conducted statistical analysis. J.P. and N.S. prepared tables and figures. N.S., A.L. and Y.L. wrote the manuscript. All these authors completely consented with all the data in the study and approved the final manuscript. A.L. and Y.L. had the primary responsibility for final manuscript.

\section{CONFLICTS OF INTEREST}

The authors declare no competing financial interests.

\section{FUNDING}

This study was supported by the grants to Dr. Shen (81601839) from the National Natural Science Foundation of China.

\section{REFERENCES}

1. Morton CC, Nance WE. Newborn hearing screening--a silent revolution. N Engl J Med. 2006; 354: 2151-64. doi: 10.1056/NEJMra050700.

2. Zelante L, Gasparini P, Estivill X, Melchionda S, D'Agruma L, Govea N, Mila M, Monica MD, Lutfi J, Shohat M, Mansfield E, Delgrosso K, Rappaport E, et al. Connexin26 mutations associated with the most common form of nonsyndromic neurosensory autosomal recessive deafness (DFNB1) in Mediterraneans. Hum Mol Genet. 1997; 6: 1605-9. doi: $10.1093 / \mathrm{hmg} / 6.9 .1605$.
3. Minami SB, Mutai H, Nakano A, Arimoto Y, Taiji H, Morimoto N, Sakata H, Adachi N, Masuda S, Sakamoto H, Yoshida H, Tanaka F, Morita N, et al. GJB2-associated hearing loss undetected by hearing screening of newborns. Gene. 2013; 532: 41-5. doi: 10.1016/j.gene.2013.08.094.

4. Han SH, Park HJ, Kang EJ, Ryu JS, Lee A, Yang YH, Lee KR. Carrier frequency of GJB2 (connexin-26) mutations causing inherited deafness in the Korean population. J Hum Genet. 2008; 53: 1022-8. doi: 10.1007/ s10038-008-0342-7.

5. Tsukada K, Nishio S, Usami S. A large cohort study of GJB2 mutations in Japanese hearing loss patients. Clin Genet. 2010; 78: 464-70. doi: 10.1111/j.1399-0004.2010.01407.x.

6. Wu CC, Tsai CH, Hung CC, Lin YH, Lin YH, Huang FL, Tsao PN, Su YN, Lee YL, Hsieh WS, Hsu CJ. Newborn genetic screening for hearing impairment: a populationbased longitudinal study. Genet Med. 2017; 19: 6-12. doi: 10.1038/gim.2016.66.

7. Kelley PM, Harris DJ, Comer BC, Askew JW, Fowler T, Smith SD, Kimberling WJ. Novel mutations in the connexin 26 gene (GJB2) that cause autosomal recessive (DFNB1) hearing loss. Am J Hum Genet. 1998; 62: 792-9. doi: 10.1086/301807.

8. Abe S, Usami S, Shinkawa H, Kelley PM, Kimberling WJ. Prevalent connexin 26 gene (GJB2) mutations in Japanese. J Med Genet. 2000; 37: 41-3. doi: 10.1136/jmg.37.1.41.

9. Kudo T, Ikeda K, Kure S, Matsubara Y, Oshima T, Watanabe K, Kawase T, Narisawa K, Takasaka T. Novel mutations in the connexin 26 gene (GJB2) responsible for childhood deafness in the Japanese population. Am J Med Genet. 2000; 90: 141-5. doi: 10.1002/(SICI)10968628(20000117)90:2<141::AID-AJMG10>3.0.CO;2-G.

10. Rabionet R, Zelante L, Lopez-Bigas N, D'Agruma L, Melchionda S, Restagno G, Arbones ML, Gasparini P, Estivill X. Molecular basis of childhood deafness resulting from mutations in the GJB2 (connexin 26) gene. Hum Genet. 2000; 106: 40-4. doi: 10.1007/s004390051007.

11. Wattanasirichaigoon D, Limwongse C, Jariengprasert C, Yenchitsomanus PT, Tocharoenthanaphol C, Thongnoppakhun W, Thawil C, Charoenpipop D, Pho-iam T, Thongpradit S, Duggal P. High prevalence of V37I genetic variant in the connexin-26 (GJB2) gene among non-syndromic hearingimpaired and control Thai individuals. Clin Genet. 2004; 66: 452-60. doi: 10.1111/j.1399-0004.2004.00325.x.

12. Huang Y, Yang XL, Chen WX, Duan B, Lu P, Wang Y, Xu ZM. Prevalence of p.V37I variant of GJB2 among Chinese infants with mild or moderate hearing loss. Int J Clin Exp Med. 2015; 8: 21674-8.

13. Huang S, Huang B, Wang G, Yuan Y, Dai P. The relationship between the p.V37I mutation in GJB2 and hearing phenotypes in Chinese individuals. PLoS One. 2015; 10: e0129662. doi: 10.1371/journal.pone.0129662.

14. Chai Y, Chen D, Sun L, Li L, Chen Y, Pang X, Zhang L, $\mathrm{Wu} \mathrm{H}$, Yang T. The homozygous p.V37I variant of GJB2 
is associated with diverse hearing phenotypes. Clin Genet. 2015; 87: 350-5. doi: 10.1111/cge.12387.

15. Huculak C, Bruyere H, Nelson TN, Kozak FK, Langlois S. V37I connexin 26 allele in patients with sensorineural hearing loss: evidence of its pathogenicity. Am J Med Genet A. 2006; 140: 2394-400. doi: 10.1002/ajmg.a.31486.

16. Chan DK, Chang KW. GJB2-associated hearing loss: systematic review of worldwide prevalence, genotype, and auditory phenotype. Laryngoscope. 2014; 124: E34-53. doi: 10.1002/lary.24332.

17. Marlin S, Garabedian EN, Roger G, Moatti L, Matha N, Lewin P, Petit C, Denoyelle F. Connexin 26 gene mutations in congenitally deaf children: pitfalls for genetic counseling. Arch Otolaryngol Head Neck Surg. 2001; 127: 927-33. doi: 10.1001/archotol.127.8.927.

18. Liu Y, Ke X, Qi Y, Li W, Zhu P. Connexin26 gene ( GJB2): prevalence of mutations in the Chinese population. J Hum Genet. 2002; 47: 688-90. doi: 10.1007/s100380200106.

19. Wu BL, Lindeman N, Lip V, Adams A, Amato RS, Cox G, Irons M, Kenna M, Korf B, Raisen J, Platt O. Effectiveness of sequencing connexin 26 (GJB2) in cases of familial or sporadic childhood deafness referred for molecular diagnostic testing. Genet Med. 2002; 4: 279-88. doi: 10.109700125817-200207000-00006.

20. Hwa HL, Ko TM, Hsu CJ, Huang CH, Chiang YL, Oong JL, Chen CC, Hsu CK. Mutation spectrum of the connexin 26 (GJB2) gene in Taiwanese patients with prelingual deafness. Genet Med. 2003; 5: 161-5. doi: 10.1097/01. gim.0000066796.11916.94.

21. Lopponen T, Vaisanen ML, Luotonen M, Allinen M, Uusimaa J, Lindholm P, Maki-Torkko E, Vayrynen M, Lopponen H, Leisti J. Connexin 26 mutations and nonsyndromic hearing impairment in northern Finland. Laryngoscope. 2003; 113: 1758-63. doi: 10.1097/00005537-200310000-00018.

22. Ohtsuka A, Yuge I, Kimura S, Namba A, Abe S, Van Laer L, Van Camp G, Usami S. GJB2 deafness gene shows a specific spectrum of mutations in Japan, including a frequent founder mutation. Hum Genet. 2003; 112: 329-33. doi: 10.1007/s00439-002-0889-x.

23. Shi GZ, Gong LX, Xu XH, Nie WY, Lin Q, Qi YS. GJB2 gene mutations in newborns with non-syndromic hearing impairment in Northern China. Hear Res. 2004; 197: 19-23. doi: 10.1016/j.heares.2004.06.012.

24. Xiao ZA, Xie DH. GJB2 (Cx26) gene mutations in Chinese patients with congenital sensorineural deafness and a report of one novel mutation. Chin Med J (Engl). 2004; 117: 1797-801.

25. Ravecca F, Berrettini S, Forli F, Marcaccini M, Casani A, Baldinotti F, Fogli A, Siciliano G, Simi P. Cx26 gene mutations in idiopathic progressive hearing loss. J Otolaryngol. 2005; 34: 126-34. doi: 10.2310/7070.2005.04017.

26. Snoeckx RL, Djelantik B, Van Laer L, Van de Heyning P, Van Camp G. GJB2 (connexin 26) mutations are not a major cause of hearing loss in the Indonesian population. Am J Med Genet A. 2005; 135: 126-9. doi: 10.1002/ajmg.a.30726.

27. Dahl HH, Tobin SE, Poulakis Z, Rickards FW, Xu X, Gillam L, Williams J, Saunders K, Cone-Wesson B, Wake M. The contribution of GJB2 mutations to slight or mild hearing loss in Australian elementary school children. J Med Genet. 2006; 43: 850-5. doi: 10.1136/jmg.2006.042051.

28. Tang HY, Fang P, Ward PA, Schmitt E, Darilek S, Manolidis $\mathrm{S}$, Oghalai JS, Roa BB, Alford RL. DNA sequence analysis of GJB2, encoding connexin 26: observations from a population of hearing impaired cases and variable carrier rates, complex genotypes, and ethnic stratification of alleles among controls. Am J Med Genet A. 2006; 140: 2401-15. doi: 10.1002/ajmg.a.31525.

29. Yang JJ, Huang SH, Chou KH, Liao PJ, Su CC, Li SY. Identification of mutations in members of the connexin gene family as a cause of nonsyndromic deafness in Taiwan. Audiol Neurootol. 2007; 12: 198-208. doi: 10.1159/000099024.

30. Chen D, Chen X, Cao K, Zuo J, Jin X, Wei C, Fang F. High prevalence of the connexin 26 (GJB2) mutation in Chinese cochlear implant recipients. ORL J Otorhinolaryngol Relat Spec. 2009; 71: 212-5. doi: 10.1159/000229300.

31. Dai P, Yu F, Han B, Liu X, Wang G, Li Q, Yuan Y, Liu X, Huang D, Kang D, Zhang X, Yuan H, Yao K, et al. GJB2 mutation spectrum in 2,063 Chinese patients with nonsyndromic hearing impairment. J Transl Med. 2009; 7: 26. doi: 10.1186/1479-5876-7-26.

32. Dalamon V, Lotersztein V, Beheran A, Lipovsek M, Diamante F, Pallares N, Francipane L, Frechtel G, Paoli B, Mansilla E, Diamante V, Elgoyhen AB. GJB2 and GJB6 genes: molecular study and identification of novel GJB2 mutations in the hearing-impaired Argentinean population. Audiol Neurootol. 2010; 15: 194-202. doi: 10.1159/000254487.

33. Schimmenti LA, Warman B, Schleiss MR, Daly KA, Ross JA, McCann M, Jurek AM, Berry SA. Evaluation of newborn screening bloodspot-based genetic testing as second tier screen for bedside newborn hearing screening. Genet Med. 2011; 13: 1006-10. doi: 10.1097/ GIM.0b013e318226fc2e.

34. Wu CC, Hung CC, Lin SY, Hsieh WS, Tsao PN, Lee CN, $\mathrm{Su}$ YN, Hsu CJ. Newborn genetic screening for hearing impairment: a preliminary study at a tertiary center. PLoS One. 2011; 6: e22314. doi: 10.1371/journal.pone.0022314.

35. Zhang J, Wang Z, Dai W, Zeng Y, Li H. GJB2 allele variants and the associated audiologic features identified in Chinese patients with less severe idiopathic hearing loss. Genet Test Mol Biomarkers. 2011; 15: 313-8. doi: 10.1089/ gtmb.2010.0182.

36. Zainal SA, Md Daud MK, Abd Rahman N, Zainuddin Z, Alwi Z. Mutation detection in GJB2 gene among Malays with nonsyndromic hearing loss. Int J Pediatr Otorhinolaryngol. 2012; 76: 1175-9. doi: 10.1016/j.ijporl.2012.04.027.

37. Chen T, Jiang L, Liu C, Shan H, Chen J, Yang B, Ou Q. Update of the spectrum of GJB2 mutations in 107 patients 
with nonsyndromic hearing loss in the Fujian population of China. Ann Hum Genet. 2014; 78: 235-42. doi: 10.1111/ ahg. 12062 .

38. Caroça C, De Matos TM, Ribeiro D, Lourenço V, Martins T, Campelo P, Fialho G, Silva SN, Paço J, Caria H. Genetic basis of nonsyndromic sensorineural hearing loss in the sub-Saharan African island population of São Tomé and Príncipe: the role of the DFNB1 locus? OMICS. 2016; 20: 449-55. doi:10.1089/omi.2016.0067.

39. Chen K, Sun L, Zong L, Wu X, Zhan Y, Dong C, Cao $\mathrm{H}$, Tang H, Jiang H. GJB2 and mitochondrial 12S rRNA susceptibility mutations in sudden deafness. Eur Arch Otorhinolaryngol. 2016; 273: 1393-8. doi: 10.1007/ s00405-015-3693-7.

40. Bruzzone R, Veronesi V, Gomes D, Bicego M, Duval N, Marlin S, Petit C, D'Andrea P, White TW. Loss-of-function and residual channel activity of connexin26 mutations associated with non-syndromic deafness. FEBS Lett. 2003; 533: 79-88. doi: 10.1016/ S0014-5793(02)03755-9.
41. Jara O, Acuna R, Garcia IE, Maripillan J, Figueroa V, Saez JC, Araya-Secchi R, Lagos CF, Perez-Acle T, Berthoud VM, Beyer EC, Martinez AD. Critical role of the first transmembrane domain of $\mathrm{Cx} 26$ in regulating oligomerization and function. Mol Biol Cell. 2012; 23: 3299-311. doi: 10.1091/mbc.E11-12-1058.

42. Chen Y, Hu L, Wang X, Sun C, Lin X, Li L, Mei L, Huang $\mathrm{Z}$, Yang T, Wu H. Characterization of a knock-in mouse model of the homozygous p.V37I variant in Gjb2. Sci Rep. 2016; 6: 33279. doi: 10.1038/srep33279.

43. Stachler RJ, Chandrasekhar SS, Archer SM, Rosenfeld RM, Schwartz SR, Barrs DM, Brown SR, Fife TD, Ford P, Ganiats TG, Hollingsworth DB, Lewandowski CA, Montano JJ, et al. Clinical practice guideline: sudden hearing loss. Otolaryngol Head Neck Surg. 2012; 146: S1-35. doi: 10.1177/0194599812436449.

44. Moher D, Liberati A, Tetzlaff J, Altman DG. Preferred reporting items for systematic reviews and meta-analyses: the PRISMA Statement. Open Med. 2009; 3: e123-30. doi: 10.1371/journal.pmed.1000097. 